\title{
Knowledge of Glasgow coma scale by air-rescue physicians Catherine Heim ${ }^{*}$, Patrick Schoettker ${ }^{1}$, Nicolas Gilliard ${ }^{1}$ and Donat R Spahn ${ }^{2}$
}

Address: ${ }^{1}$ Department of Anesthesiology, Centre Hospitalier Universitaire Vaudois (CHUV), Lausanne, Switzerland and ${ }^{2}$ Department of Anesthesiology, University Hospital, Zurich, Switzerland

Email: Catherine Heim* - catherine.heim@chuv.ch; Patrick Schoettker - patrick.schoettker@chuv.ch; Nicolas Gilliard - nicolas.gilliard@chuv.ch; Donat R Spahn - donat.spahn@usz.ch

* Corresponding author

\section{Published: I September 2009}

Scandinavian Journal of Trauma, Resuscitation and Emergency Medicine 2009, 17:39 doi:10.1186/1757-7241-17-39

This article is available from: http://www.sjtrem.com/content/17/I/39

(c) 2009 Heim et al; licensee BioMed Central Ltd.

This is an Open Access article distributed under the terms of the Creative Commons Attribution License (http://creativecommons.org/licenses/by/2.0), which permits unrestricted use, distribution, and reproduction in any medium, provided the original work is properly cited.
Received: 2 June 2009

Accepted: I September 2009

\begin{abstract}
Objective: To assess the theoretical and practical knowledge of the Glasgow Coma Scale (GCS) by trained Air-rescue physicians in Switzerland.

Methods: Prospective anonymous observational study with a specially designed questionnaire. General knowledge of the GCS and its use in a clinical case were assessed.

Results: From 130 questionnaires send out, 103 were returned (response rate of $79.2 \%$ ) and analyzed. Theoretical knowledge of the GCS was consistent for registrars, fellows, consultants and private practitioners active in physician-staffed helicopters. The clinical case was wrongly scored by 38 participants (36.9\%). Wrong evaluation of the motor component occurred in 28 questionnaires (27.2\%), and 19 errors were made for the verbal score (18.5\%). Errors were made most frequently by registrars $(47.5 \%, p=0.09)$, followed by fellows $(31.6 \%, p=0.67)$ and private practitioners $(18.4 \%, p=1.00)$. Consultants made significantly less errors than the rest of the participating physicians $(0 \%, p<0.05)$. No statistically significant differences were shown between anesthetists, general practitioners, internal medicine trainees or others.
\end{abstract}

Conclusion: Although the theoretical knowledge of the GCS by out-of-hospital physicians is correct, significant errors were made in scoring a clinical case. Less experienced physicians had a higher rate of errors. Further emphasis on teaching the GCS is mandatory.

\section{Introduction}

The Glasgow Coma Scale (GCS) was developed more than thirty years ago as a practical tool to measure the "depth and duration of impaired consciousness" [1]. Simplicity was the principle concern with the goal to provide a method to quantify and communicate reliable information about level of consciousness. Thirty years after its initial publication, it has reached worldwide acceptance for assessment and description of patients with neurological impairment [2-4]. In the out-of-hospital setting, the GCS is an important tool for decision-making and triage and its initial score acts as an important prognostic indicator after traumatic brain injury (TBI) [5-8].

The correct assessment of the GCS shows variability among providers and it's assessment has been shown to be difficult with variable implications on treatment [911]. Patients on scene are often unstable and more difficult to assess [12]. The reliability of GCS scoring is thus particularly important in this context as it is used to make airway management and disposition decisions [13]. The out-of-hospital GCS is also of value for the attending neu- 
rosurgeon and emergency physician when an emergency department GCS cannot be obtained, due to endotracheal intubation and/or neuromuscular paralysis [14]. Inaccurate reporting may result in unnecessary treatment and diagnostic tests. In addition to the summed value, each component of the three categories of the GCS should also be reported [15].

In Switzerland, as in most Europeans countries, out-ofhospital trauma care is provided by physicians on board helicopters or fast-response cars $[16,17]$. The qualifications of the on-board physicians vary between registrars to consultants and their specialty may be anesthesia, general medicine, internal medicine or others.

The purpose of this study is to assess the knowledge among Swiss air-rescue physicians of the Glasgow Coma Scale by using a specially designed questionnaire.

\section{Materials and methods}

A questionnaire to assess GCS knowledge (additional file 1) was designed by the two first authors of the study. It consisted of two parts:

1. Questions of general nature about the physicians' training and the GCS

Level of training/number of years of practice

Participant's specialty

Familiarity of the participants with the GCS

Knowledge and description of its structure

Knowledge and description of its individual components

\section{Description of a clinical scenario}

Assessment of a patient having sustained a traumatic brain injury with questions about his GCS and the number of points per component

The medical director of each of the 18 helicopter-bases of the Swiss air-rescue system received a phone call from the first author explaining the purpose and the method of the study. The questionnaires were then sent with a cover letter to the medical director who mailed them to every physician working for his organization in May 2004. Each participant was asked to answer the questionnaire without help and in less than 10 minutes. After completion, the questionnaire was sent back anonymously to the medical director who then returned them to the first author within one month. A reminder phone call was made by the first author two weeks after having sent the questionnaire. Participants were defined as registrars if they were in training, fellows if they had completed their training and were specializing in a sub-specialty, consultants if they were qualified specialists with teaching positions and in private practice if they had left the hospital setting and worked as independent specialists.

\section{Statistical analysis}

Data were analyzed using the JMP 6 statistical package (SAS Institute, Inc, Cary, NC). We used the Fisher's exact test to determine significance between subgroups by rater experience (registrar, fellow, consultant and private practice) or physician's specialization (anesthesia, internal medicine, general practice, others). Data were assessed as non parametric and thus indicated as median $\left[25^{\text {th }}-75^{\text {th }}\right.$ percentiles]. Results were considered statistically significant when $\mathrm{p}<0.05$.

\section{Results}

A total of 130 questionnaires were sent to the medical directors of the 18 helicopter bases. Two of the helicopter bases did not participate. The overall response rate from the 16 participating helicopter bases was 79.2\% (103 questionnaires). All of the questionnaires returned were complete without any missing data. None of the answered questionnaires had to be excluded.

The Swiss helicopters are staffed mainly by registrars and fellows, mostly with an anesthetic background (table 1). The median clinical experience of all participants is 9.0 years with the anesthetists being the most junior in their training. Median clinical experience of registrars is 5.5 years [IQR 4-7], while the other categories have a median experience of 10 years or more (table 2 ).

All of the participating physicians knew about the GCS and were aware of its three components; six physicians $(5.8 \%)$ incorrectly named one or two components (one error for the eye component, two errors for the motor and four errors for the verbal component) and four participants $(3.9 \%)$ attributed the wrong number of points to them. The minimal score was described as 3 by $100 \%$ of the participants and the maximum score of 15 by all but one physician (99\%).

The clinical case showed incorrect scoring of the overall GCS by 38 physicians (36.9\%). While the correct answer was a summed GCS-score of 6 , the answers ranged from 4 to 8 (figure 1 ).

The errors in the assessment of the clinical case by the level of training are shown in table 3 . Registrars accounted for $38.8 \%$ of the helicopter physicians and were responsible for $50.0 \%$ of the total errors. In comparison with fel- 
Table I: Demographic data

\begin{tabular}{|c|c|c|c|}
\hline & & $n$ & $\%$ \\
\hline Questionnaires sent & & 130 & 100 \\
\hline Questionnaires returned & & 103 & 79.2 \\
\hline \multicolumn{4}{|l|}{ Grade } \\
\hline & Registrar & 40 & 38.8 \\
\hline & Fellow & 36 & 35.0 \\
\hline & Private practice & 19 & 18.5 \\
\hline & Consultant & 8 & 7.7 \\
\hline \multicolumn{4}{|l|}{ Specialty } \\
\hline & Anesthesia & 63 & 61.2 \\
\hline & General medicine & 19 & 18.5 \\
\hline & Internal medicine & 17 & 16.5 \\
\hline & Others & 4 & 3.9 \\
\hline
\end{tabular}

lows, consultants and private practitioners, registrars tended to make more errors $(\mathrm{p}=0.095)$. Among the anesthetists, registrars made significantly more errors in the case analysis $(\mathrm{p}=0.039)$ than their more experienced colleagues of the same specialty. The private practitioners (18.5\% of the helicopter physicians) were responsible of $18.4 \%$ of the errors $(\mathrm{p}=1.00)$, whereas the fellows
(35.0\% of the helicopter physicians) made $31.6 \%$ of the errors in the clinical scenario $(\mathrm{p}=0.671)$. The consultants made significantly less errors in assessing the clinical case $(0 \%, \mathrm{p}<0.05)$.

The percentage of errors in assessing the clinical case also varied among the different specialties without attaining statistically significant values. Anesthetists assessed incorrectly the case in $39.7 \%$, physicians of internal medicine in $29.4 \%$, those of general medicine in $31.6 \%$ and others in $50 \%$.

Differences in assessing the three individual components of the clinical scenario were noted. The motor component score was assessed incorrectly in 28 cases $(27.2 \%)$, the verbal component in 19 cases (18.5\%), while the ocular score was always assessed correctly. Errors were made in assessing both the motor and the verbal component in 8 cases $(7.8 \%)$ (figure 2$)$. Registrars tended to make more errors in assessing the motor score $(p=0.07)$ in comparison with fellows $(\mathrm{p}=0.818)$, consultants $(\mathrm{p}=0.104)$ and private practitioners $(\mathrm{p}=0.582)$. Again there was no statistically significant difference in assessing the motor score among subgroups of specialty and level of training.

\section{Discussion}

This study shows that although the GCS is a commonly used tool to assess level of consciousness, more than onethird of air-rescue physicians in Switzerland imprecisely scored it, making errors essentially in the assessment of the motor response.

This is the only study in the medical literature investigating knowledge of the GCS among trained out-of-hospital

Table 2: Clinical experience of participants by specialty and by grade

\begin{tabular}{|c|c|c|}
\hline Mean clinical experience by specialty & Years, median & IQR [25-75] \\
\hline Anesthesia & 8.0 & $5.0-10.25$ \\
\hline General Medicine & 10.0 & $8-19$ \\
\hline Internal Medicine & 10.0 & $7-12$ \\
\hline Others & 12.0 & $4.75-25.25$ \\
\hline Mean clinical experience by grade & Years, median & IQR [25-75] \\
\hline Registrar & 5.5 & $4-7$ \\
\hline Fellow & 15.5 & $11.75-18.75$ \\
\hline Consultant & 10.0 & $8-12$ \\
\hline Private practice & 15.0 & $10-19.5$ \\
\hline
\end{tabular}




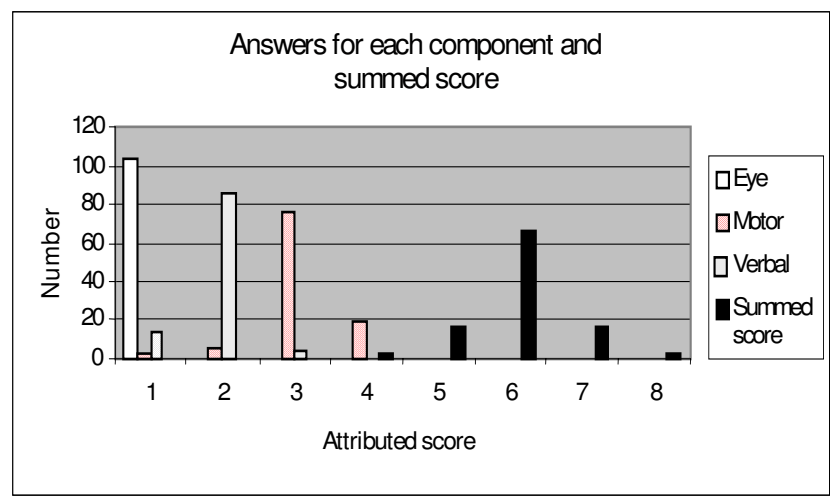

Figure I

Range of answers for the clinical case. Correct value for eye-score: I. Correct value for motor-score: 3. Correct value for verbal-score: 2 . Correct value for summed score: 6 . physicians. So far, most of the studies evaluating the assessment of the GCS were investigating groups of trained versus untrained staff, paramedics versus physicians or nurses. Our study compares physicians working in the emergency air-rescue-system of Switzerland.

All of the participants had proper theoretical knowledge of the GCS. This validates the wide application and theoretical knowledge of the score in the out-of-hospital setting.

We observed an incorrect assessment of the GCS in the clinical scenario by $36.9 \%$ of the participating physicians. Errors were associated with level of training, with registrars being responsible for $50 \%$ of all errors. This reached statistical significance in the anesthesia group when compared with their more experienced colleagues.

Table 3: Distribution of errors in assessment of clinical case by grade and specialty

\begin{tabular}{|c|c|c|c|c|}
\hline Grade & Specialty & $\mathbf{n}$ & Errors in numbers & Errors in \% \\
\hline \multirow[t]{2}{*}{ Registrar $(n=40)$} & Anesthesia & 29 & 15 & 51.7 \\
\hline & Internal medicine & 4 & 2 & 50 \\
\hline \multirow[t]{3}{*}{$p=0.095^{*}$} & General practice & 6 & 1 & 16.7 \\
\hline & Others & 1 & 1 & 100 \\
\hline & Total & 40 & 19 & 47.5 \\
\hline \multirow[t]{2}{*}{ Fellow $(n=36)$} & Anesthesia & 27 & 10 & 37 \\
\hline & Internal medicine & 7 & 1 & 14.3 \\
\hline \multirow[t]{3}{*}{$P=0.67 I^{*}$} & General practice & I & 0 & 0 \\
\hline & Others & 1 & 1 & 100 \\
\hline & Total & 36 & 12 & 33.3 \\
\hline \multirow[t]{2}{*}{ Consultant $(n=8)$} & Anesthesia & 7 & 0 & 0 \\
\hline & Internal medicine & 1 & 0 & 0 \\
\hline \multirow[t]{3}{*}{$\mathrm{P}=0.025^{*}$} & General practice & 0 & 0 & 0 \\
\hline & Others & 0 & 0 & 0 \\
\hline & Total & 8 & 0 & 0 \\
\hline \multirow[t]{2}{*}{ Private practice $(n=19)$} & Anesthesia & 0 & 0 & 0 \\
\hline & Internal medicine & 5 & 2 & 40 \\
\hline \multirow[t]{3}{*}{$p=1.00 *$} & General practice & 12 & 5 & 41.7 \\
\hline & Others & 2 & 0 & 0 \\
\hline & Total & 19 & 7 & 36.8 \\
\hline
\end{tabular}

\footnotetext{
*: p-value of each individual grade-category versus the others
} 


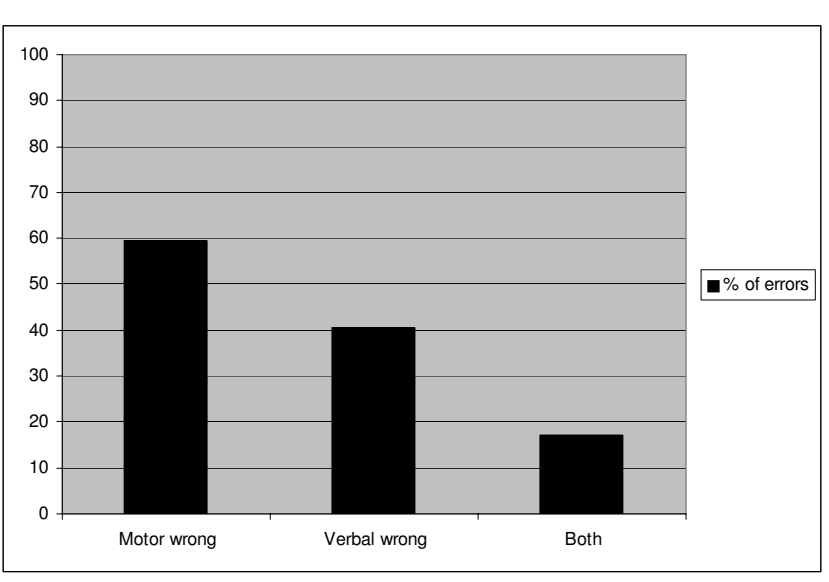

Figure 2

Distribution of errors in the wrong evaluation of components of the clinical case.

Consultants, who have teaching positions in the Swiss system, made significantly less errors in scoring the clinical scenario. A German study by Lackner et al. analyzed different cohorts of emergency medical staff including physicians, medical students and paramedics on scoring the GCS in video-sequences [18]. They concluded that the level of medical education and professional exposure to trauma patients had a major impact of the accuracy of scoring neurological impairment. Our study included only graduated medical physicians and all of them are regularly exposed to trauma patients.

None of the different specialties investigated was prone to make significantly more errors in the clinical case than another, independently of their level of training.

Previous studies have described variability in the difficulty of scoring the three components of the GCS. [19-21] In this study, the eye component was correctly scored by all participants. This might be consistent with the findings of other authors, who described best accuracy in very high or very low scores [11]. The motor component, with its 6 possibilities, has been shown the most difficult to assess. Among others, the way of eliciting motor response is prone to debate and authors report limb rather than central stimulation. We used truncal stimulation as this was standard at the time of the study. This has been changed since then. Growing evidence suggests that the motor component alone could prove useful for predicting outcome and accurately triaging patients in the trauma setting $[8,22-24]$. In our study errors in assessing the latter component were responsible for more than half of the errors: again, the lower the experience level of the physician, the more prone to errors. The number of errors in scoring the total GCS of the clinical case was lower than the errors made in scoring the components individually. This indicates the imprecise nature of the summed score.
A limitation of our study is the modality of investigation by questionnaire, which cannot create the same stressful situation as might be experienced at the scene of the accident. Also it was requested that participants fill out the questionnaire without external help and within a time limit of 10 minutes. The study design does not allow assessment of the rate of compliance with these instructions.

Another limitation is the use of only one clinical scenario to evaluate our participants. Although better reliability might have been achieved with several cases, we aimed at obtaining a high response rate and therefore opted for a low time-consuming questionnaire. Menegazzi et al. found significant interrater agreement at higher GCS scores and only a moderate agreement at intermediate or low GCS values [25] whereas Rowley et al. found the best agreement in very high or very low GCS scores with greatest discrepancies in intermediate values [11]. We intentionally chose a clinical case of a severe traumatic head injury in the lower intermediate range, as studies have shown that there is a steep relationship between GCS 3 and 7 and mortality, followed by a shallower decline between 8 and 15 [26].

Finally, we do not know the level of training nor the distribution of specialties among the non responders to the questionnaire. This might possibly alter the conclusion.

\section{Conclusion}

More than a third of the air-rescue physicians in Switzerland imprecisely scored the Glasgow coma scale in this study. Mistakes occur mainly in the assessment of the motor response followed by the verbal response while the eye component did not generate any wrong answers. In some cases, although the summed score was correct, it was calculated from incorrectly scored components. An association was found between performance and the level of training, with registrars producing more errors in scoring than their more experienced colleagues. However there was no difference between specialties.

This study indicates the need for education to reduce variability in GCS-Scoring. The GCS is an important score for clinical decision making and prognostication. Better training in prehospital scoring of the GCS is necessary.

\section{Competing interests}

The authors declare that they have no competing interests.

\section{Authors' contributions}

$\mathrm{CH}$ is the first author who designed the study, wrote the questionnaire, analyzed the results and wrote the manuscript. PS contributed substantially to the design of the study, it's coordination, it's analysis, the manuscript and the statistical approach. DRS contributed to the feasibility 
of the study and reviewed the manuscript and the statistical approach. NG contributed to the feasibility and coordination of the study and reviewed the manuscript text. All authors read and approved the final manuscript.

\section{Additional material}

\section{Additional file 1}

Questionnaire. The data provided represent the questionnaire sent to all participating helicopter bases.

Click here for file

[http://www.biomedcentral.com/content/supplementary/17577241-17-39-S1.doc]

\section{Acknowledgements}

The authors thank Philippe Frascarolo, $\mathrm{PhD}$, for his statistical assistance.

\section{References}

I. Teasdale G, Jennett B: Assessment of coma and impaired consciousness. A practical scale. Lancet 1974, 2:8I-4.

2. Choi SC, Narayan RK, Anderson RL, Ward JD: Enhanced specificity of prognosis in severe head injury. J Neurosurg 1988, 69:38I-5.

3. Segatore M, Way C: The Glasgow Coma Scale: time for change. Heart Lung 1992, 2 I:548-57.

4. Guzzo JL, Bochicchio GV, Napolitano LM, Malone DL, Meyer W, Scalea TM: Prediction of outcomes in trauma: anatomic or physiologic parameters? J Am Coll Surg 2005, 20 I:89I-7.

5. Bouillon B, Kramer M, Tiling T, Neugebauer E: [Trauma score systems as instruments in quality control. A prospective study on validation of 7 trauma score systems with $6 I 2$ trauma patients]. Unfallchirurg 1993, 96:55-61.

6. Teasdale GM, Pettigrew LE, Wilson JT, Murray G, Jennett B: Analyzing outcome of treatment of severe head injury: a review and update on advancing the use of the Glasgow Outcome Scale. J Neurotrauma 1998, I 5:587-97.

7. American College of Surgeons Committee of Trauma: Advanced Trauma Life Suppport. 8th edition. 2008.

8. Al-Salamah MA, McDowell I, Stiell IG, Wells GA, Perry J, Al-Sultan M, Nesbitt $L$ : Initial emergency department trauma scores from the OPALS study: the case for the motor score in blunt trauma. Acad Emerg Med 2004, I I :834-42.

9. Marion DW, Carlier PM: Problems with initial Glasgow Coma Scale assessment caused by prehospital treatment of patients with head injuries: results of a national survey. J Trauma 1994, 36:89-95.

10. Chen LM, Martin CM, Morrison TL, Sibbald WJ: Interobserver variability in data collection of the APACHE II score in teaching and community hospitals. Crit Care Med 1999, 27:1999-2004.

II. Rowley G, Fielding K: Reliability and accuracy of the Glasgow Coma Scale with experienced and inexperienced users. Lancet 1991, 337:535-8.

12. Kerby JD, MacLennan PA, Burton JN, McGwin G Jr, Rue LW 3rd: Agreement between prehospital and emergency department glasgow coma scores. JTrauma 2007, 63:|026-3I.

13. Guidelines for the management of severe head injury. Brain Trauma Foundation, American Association of Neurological Surgeons, Joint Section on Neurotrauma and Critical Care. J Neurotrauma 1996, I 3:641-734.

14. Servadei F, Nasi MT, Cremonini AM, Giuliani G, Cenni P, Nanni A: Importance of a reliable admission Glasgow Coma Scale score for determining the need for evacuation of posttraumatic subdural hematomas: a prospective study of $\mathbf{6 5}$ patients. J Trauma 1998, 44:868-73.

15. Teoh LS, Gowardman JR, Larsen PD, Green R, Galletly DC: Glasgow Coma Scale: variation in mortality among permutations of specific total scores. Intensive Care Med 2000, 26:157-6I.
16. Schoettker $\mathrm{P}$, Ravussin $\mathrm{P}$, Moeschler $\mathrm{O}$ : Ejection as a key word for the dispatch of a physician staffed helicopter: the Swiss experience. Resuscitation 2001, 49:169-73.

17. Schoettker P, Potin M, Staeger P, Fuchs V, Yersin B, Ribordy V: [An efficient example of a Swiss pre-hospital chain of survival: the state of Vaud model]. Rev Med Suisse 2006, 2:1849-53.

18. Lackner CR, M Lazarovici, M Stolpe E: Anwenderperformanz und variabilität der Glasgow-Koma-Skala. Nottfall und Rettungsmedizin 2002, 5: I73-85.

19. Healey C, Osler TM, Rogers FB, Healey MA, Glance LG, Kilgo PD, Shackford SR, Meredith JW: Improving the Glasgow Coma Scale score: motor score alone is a better predictor. J Trauma 2003, 54:67I-8. discussion 8-80.

20. Buechler CM, Blostein PA, Koestner A, Hurt K, Schaars M, McKernan J: Variation among trauma centers' calculation of Glasgow Coma Scale score: results of a national survey. J Trauma I998, 45:429-32.

21. Holdgate $A$, Ching $N$, Angonese L: Variability in agreement between physicians and nurses when measuring the Glasgow Coma Scale in the emergency department limits its clinical usefulness. Emerg Med Australas 2006, 18:379-84.

22. Ross SE, Leipold C, Terregino C, O'Malley KF: Efficacy of the motor component of the Glasgow Coma Scale in trauma triage. J Trauma 1998, 45:42-4.

23. Meredith W, Rutledge R, Hansen AR, Oller DW, Thomason M, Cunningham $\mathrm{P}$, Baker CC: Field triage of trauma patients based upon the ability to follow commands: a study in 29,573 injured patients. J Trauma 1995, 38: I29-35.

24. Combes P, Fauvage B, Colonna M, Passagia JG, Chirossel JP, Jacquot $C$ : Severe head injuries: an outcome prediction and survival analysis. Intensive Care Med 1996, 22:|39|-5.

25. Menegazzi J], Davis EA, Sucov AN, Paris PM: Reliability of the Glasgow Coma Scale when used by emergency physicians and paramedics. J Trauma 1993, 34:46-8.

26. Udekwu P, Kromhout-Schiro S, Vaslef S, Baker C, Oller D: Glasgow Coma Scale score, mortality, and functional outcome in head-injured patients. J Trauma 2004, 56: I084-9.
Publish with Bio Med Central and every scientist can read your work free of charge

"BioMed Central will be the most significant development for disseminating the results of biomedical research in our lifetime. "

Sir Paul Nurse, Cancer Research UK

Your research papers will be:

- available free of charge to the entire biomedical community

- peer reviewed and published immediately upon acceptance

- cited in PubMed and archived on PubMed Central

- yours - you keep the copyright
BioMedcentral 